Copyright (C) 2016 by Academic Publishing House Researcher

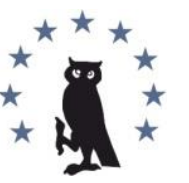

Published in the Russian Federation

European Researcher

Has been issued since 2010.

ISSN 2219-8229

E-ISSN 2224-0136

Vol. 106, Is. 5, pp. 242-251, 2016

DOI: 10.13187/er.2016.106.242

www.erjournal.ru

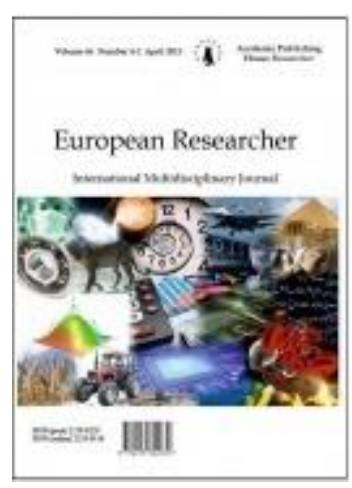

Economic sciences

Экономические науки

UDC 615.473.9:615.835.5; 33

\title{
Studying the Factors Influencing a Choice of Devices for Carrying Out Inhalations on the Basis of Statistical Processing of Results Of Questionnaire
}

${ }^{1}$ Galina A. Kharchenko

${ }^{2}$ Marina Yu. Klischenko

3 Irina V. Grigorieva

4 Vladimir V. Kovalenko

5 Svetlana V. Semenova

${ }^{1}$ Ryazan state medical university, Russian Federation

Vysokovoltnaya Str., 9 Ryazan city 390026

$\mathrm{PhD}$ (biological), associate professor

E-mail: kmarina62@mail.ru

${ }^{2}$ Ryazan State Medical University, Russian Federation

Vysokovoltnaya Str., 9 Ryazan city 390026

Assistant

E-mail: kmarina62@mail.ru

3 Ryazan state medical university, Russian Federation

Vysokovoltnaya Str., 9 Ryazan city 390026

$\mathrm{PhD}$ (pharmaceutical), associate professor

E-mail: i.grigorieva62@mail.ru

4 Sochi state university, Russian Federation

Sovetskaya Str., 26a, Sochi city, Krasnodar krai 354000

$\mathrm{PhD}$ (technical), associate professor

E-mail:vlvas@mail.ru

${ }^{5}$ Ryazan State Medical University, Russian Federation

Vysokovoltnaya Str., 9 Ryazan city 390026

Assistant professor

E-mail: SV-tmb@yandex.ru

\footnotetext{
Abstract

Authors set the object, to study the factors influencing a choice of buyers of devices for carrying out inhalation on the basis of statistical processing of results of questionnaire of buyers, to analyze interrelation between the factors influencing a choice and purchase of the device and gender and age characteristics of potential buyers. The role of the doctor, worker of a drugstore, the
} 
Internet sites in the course of a choice, opinion of consumers of different age categories on the most preferable sources of information on devices for carrying out inhalation is revealed, preferences of buyers at a choice of a place of commission of purchase of devices for carrying out inhalation are defined. Feature of respondents of sources of information and making decision on purchase, female and male concerning use is shown.

Keywords: devices for carrying out inhalation; consumer properties; statistical processing; questionnaire market researches; pharmaceutical organization.

\section{Введение}

В настоящее время существует несколько типов систем доставки лекарственного средства в дыхательные пути: дозированные ингаляторы (порошковые, аэрозольные, жидкостные, их комбинации со спейсерами), паровлажные ингаляторы и небулайзеры (ультразвуковые, компрессорные, электронно-сетчатые, мембранные (или мешнебулайзеры)).

До недавнего времени процедуры ингаляции пациенты применяли, в основном, в медицинских организациях. Современные технологии позволили создать аппараты для проведения ингаляций в домашних условиях, что обеспечило рост их популярности среди врачей и пациентов.

Применение аппаратов для проведения ингаляции в лечении различных заболеваний верхних дыхательных путей и легких является одним из наиболее важных направлений в современной медицинской практике. Лекарственный препарат (ЛП), распыляемый ингалятором, минует желудочно-кишечный тракт, печень, кровеносную систему и лекарственные вещества в неизмененном виде действует непосредственно на очаг воспаления. Кроме того, минуя печень, ЛП действуют более эффективно и в меньших дозах, чем при их пероральном применении и иных способах введения. При этом он не оказывает побочного действия, характерного для парентерального и перорального применения. Простота процедуры проведения ингаляции заключается в том, что не требуется координации вдоха и ввода ЛП, что особенно важно для пожилых, тяжелобольных людей и детей.

Промышленностью выпускаются разнообразные ингаляционные системы - от обычных паровых до суперсовременных мембранных, «продвинутых» в технологическом плане. Покупателям сложно в этом многообразии подобрать оптимальный по цене, качеству, комплектности (наличие насадок, масок и др.) аппарат, необходимо тщательно изучить информацию о предлагаемых аппаратах, проконсультироваться с врачом и специалистами аптечных организациях, многие покупатели внимательно изучают информацию на интернет-сайтах. В этом аспекте интересно проведение исследования потребительских предпочтений.

Анкетирование покупателей аппаратов для проведения ингаляций позволяет оценить основных потребителей продукции, их половозрастные характеристики, предпочтения и др. и правильно проводить планирование ассортимента продукции и ценовую политику организации.

Целью данной работы является изучение факторов, влияющих на выбор покупателей при покупке аппаратов для проведения ингаляции и на основе анкетного опроса покупателей решить следующие задачи:

1. выявить основные источники информации при принятии решения о необходимости приобретения аппаратов для проведения ингаляции;

2. выявить роль врача, работника аптеки, интернет-сайтов, средств массовой информации (СМИ) в процессе выбора;

3. выявить мнение потребителей о наиболее предпочтительных источниках информации об аппаратах для проведения ингаляции,

4. определить предпочтения покупателей разных возрастных категорий, места совершения покупки аппаратов для проведения ингаляции.

Гипотезой (нулевой) исследования является выявление отсутствия различий в оценке факторов, влияющих на выбор аппаратов для проведения ингаляций разных групп потребителей (покупателей). 


\section{Материалы и методы}

Анкетирование находит широкое применение в разных областях медицины $[1,2,3]$ и фармации $[4,5,6,7,8,9]$. Анкетирование, как метод маркетинговых исследований, используется для определения потребительских предпочтений покупателей различных видов товаров. Анкетирование является быстрым и достаточно точным способом получения информации об отношении покупателей к процессу выбора, покупки и дальнейшего использования товаров.

Было проведено анкетирование 107 респондентов - посетителей аптечных организаций центральных регионов Российской Федерации. Анкетировались только те посетители, целью которых было приобретение ингаляционной техники.

Анкета включала в себя вопросы с представленными для выбора вариантами ответов типа тестового задания. Данные, полученные в результате анкетирования, относятся к типу номинальных данных. Поэтому их статистическая обработка выполнялась на основе таблиц сопряженности в среде пакета "Statistica". Авторы и ранее успешно использовали данный метод в своих исследованиях $[10,11,12,13,14,15,16]$.

\section{Обсуждение результатов}

Анализ ответов респондентов показал, что в ряде случаев принимается нулевая гипотеза, поэтому указанные ниже комбинации вопроса и страта исключены из обсуждения:

- достоверно ли различаются ответы на вопрос «по чьей рекомендации Вы приобрели ингалятор?» в зависимости от пола респондента;

- достоверно ли различаются ответы на вопрос «по чьей рекомендации Вы приобрели ингалятор?» в зависимости от наличия у членов семьи хронических бронхолегочных заболеваний).

Анализ общих характеристик респондентов по принадлежности к определенному полу и возрастным группам показал, что 83,17 \% общего числа анкетируемых представительницы прекрасного пола, по возрастным группам респонденты поделились почти на равные доли (рис. 1). Около половины респондентов имеют хронические бронхолегочные заболевания (50,94\%).

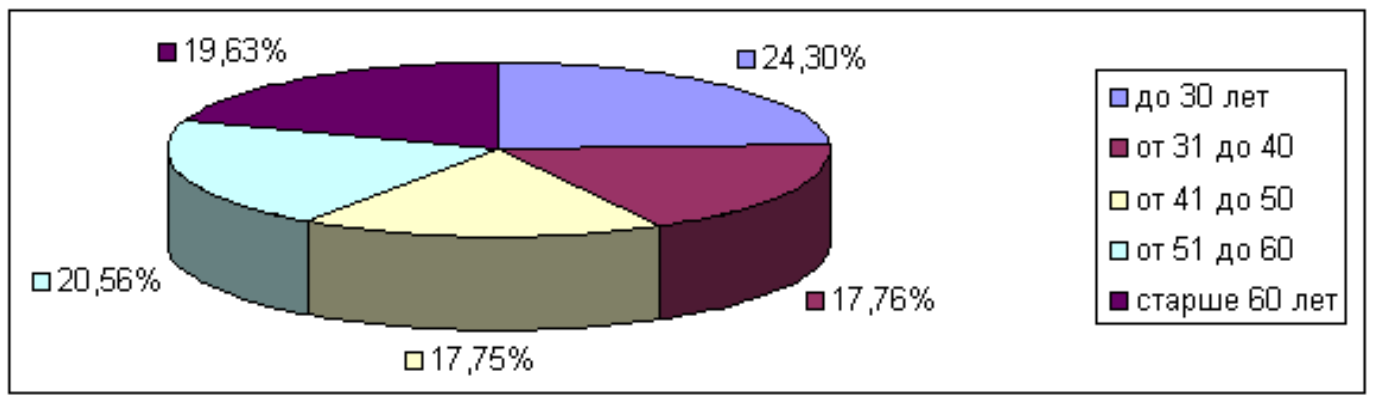

Рис. 1. Распределение респондентов по возрастам

Анализ ответов на вопрос «По чьей рекомендации был приобретен аппарат для проведения ингаляции?» показал, что основная масса респондентов покупает ингаляторы по рекомендации врача (рис. 2.). 


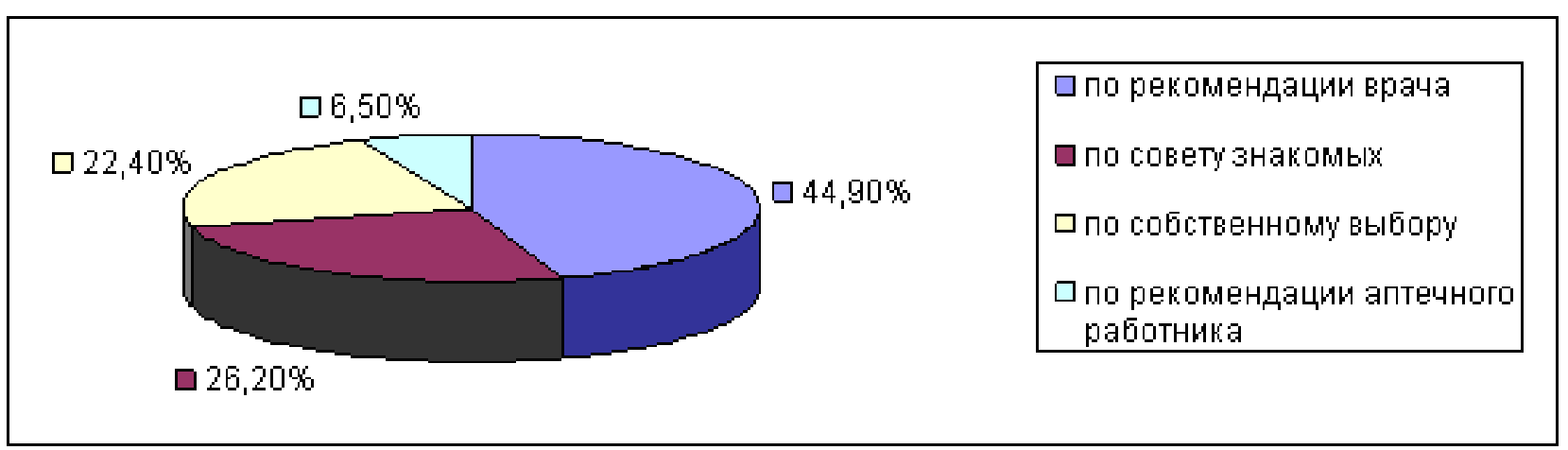

Рис. 2. Распределение респондентов по рекомендующим источникам при решении о необходимости покупки

Советам знакомых, пользующихся ингаляторами (удобно, экономично, минимум побочных эффектов и т.д.) следуют 26,2 \% респондентов. На собственном выборе основываются 22,4 \%, понимая, что ингаляционная терапия имеет множество преимуществ перед традиционным лечением заболеваний дыхательных путей (таблетки, микстуры, капли для приема внутрь, и пр.). Рекомендациям врача последовали 44,5 \% опрошенных потребителей, аптечного работника $-6,5 \%$.

Крайне важно отметить роль врача в рекомендации использовать аппараты для проведения ингаляции при частой заболеваемости острыми респираторными инфекциями, сопровождающимися кашлем; наличии заболеваний, требующих проведения ингаляционной терапии (хронический обструктивный бронхит, бронхиальная астма и др.).

На чей совет в большей степени полагались женщины и чью рекомендацию предпочли мужчины обсудить не представляется возможным, так как в данном вопросе не существует достоверных различий по зависимости того или другого варианта ответа от пола респондента.

Когда же речь идет о выборе типа ингаляционной техники (рис. 3), большинство респондентов полагается на мнение аптечного работника $(48,59 \%)$, далее следуют официальные Интернет-сайты (22,42 \%), затем средства массовой информации - далее СМИ $(13,08 \%)$.

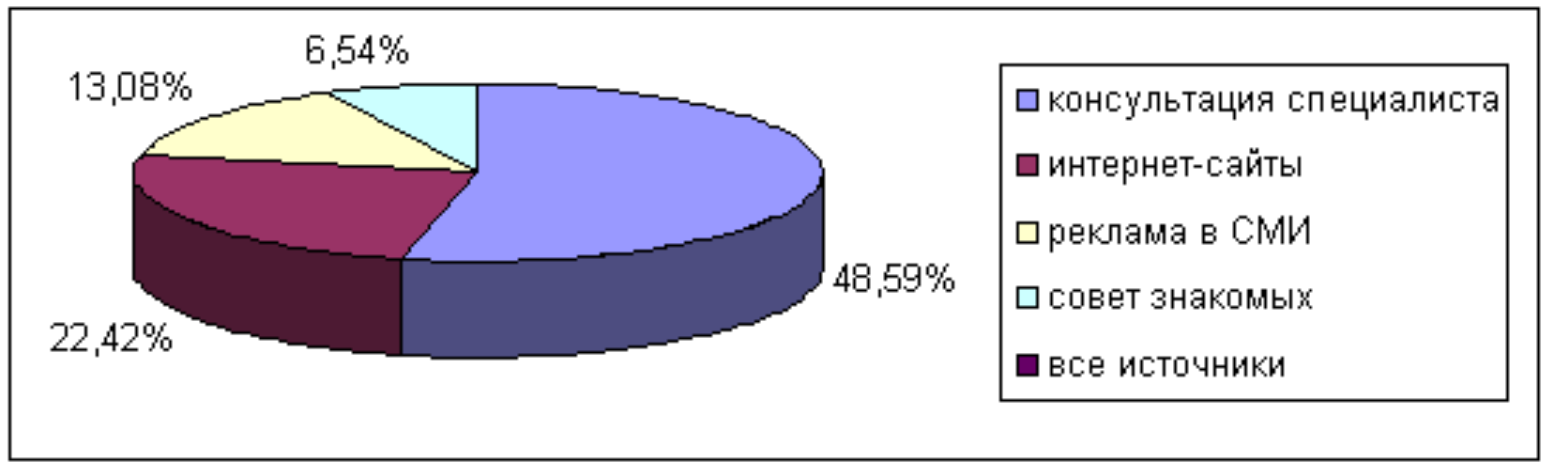

Рис. 3. Распределение респондентов по рекомендующим источникам при выборе типа ингалятора

Для женщин наиболее важным при покупке ингалятора является консультация специалиста (работника аптеки, консультанта медицинской техники) (50,56 \%), на данные сети Интернет обращают внимание 19,10 \% покупательниц (табл.1). Мужчины в равной степени доверяют как специалистам, так и информации, размещенной в системе Интернета. Женщины в большей степени подвержены воздействию рекламы, чем мужчины.

Наблюдается принципиально разный подход к решению данной проблемы в зависимости от пола респондентов: 11,24 \% женщин перед покупкой воспользовались всеми возможными источниками информации и затем приняли решение, все мужчины сначала выбрали источник информации и полностью на него положились. 
Таблица 1. Таблица сопряженности для признаков: источник информации и пол респондента

\begin{tabular}{|c|c|c|c|c|c|c|}
\hline \multirow[b]{2}{*}{ Пол } & \multicolumn{6}{|c|}{ Источник информации } \\
\hline & $\begin{array}{l}\text { консультация } \\
\text { специалиста }\end{array}$ & $\begin{array}{c}\text { данные } \\
\text { официальных } \\
\text { интернет- } \\
\text { сайтов } \\
\text { производит } \\
\text { елей } \\
\end{array}$ & $\begin{array}{c}\text { реклама } \\
\text { в СМИ }\end{array}$ & $\begin{array}{c}\text { совет } \\
\text { знакомых }\end{array}$ & $\begin{array}{c}\text { все } \\
\text { источники }\end{array}$ & Всего \\
\hline женский & 45 & 17 & 13 & 4 & 10 & 89 \\
\hline$\%$ & $50,56 \%$ & $19,10 \%$ & $14,61 \%$ & $4,49 \%$ & $11,24 \%$ & \\
\hline мужской & 7 & 7 & 1 & 3 & $\mathrm{O}$ & 18 \\
\hline$\%$ & $38,89 \%$ & $38,89 \%$ & $5,56 \%$ & $16,67 \%$ & $0,00 \%$ & \\
\hline Итого & $52(48,59 \%)$ & $24(22,42 \%)$ & $\begin{array}{c}14 \\
(13,08 \%)\end{array}$ & $7(6,54 \%)$ & $10(9,35 \%)$ & 107 \\
\hline
\end{tabular}

Представляет интерес анализ возрастных предпочтений по источникам используемой информации (табл. 2).

Таблица 2. Таблица сопряженности для признаков: тип ингалятора и возраст респондентов

\begin{tabular}{|c|c|c|c|c|c|c|}
\hline \multirow[b]{2}{*}{$\begin{array}{l}\text { Возраст } \\
\text { (лет) }\end{array}$} & \multicolumn{6}{|c|}{ Источник информации } \\
\hline & $\begin{array}{c}\text { консульта- } \\
\text { ция } \\
\text { специалиста }\end{array}$ & $\begin{array}{c}\text { данные } \\
\text { официальных } \\
\text { интернет- } \\
\text { сайтов }\end{array}$ & $\begin{array}{c}\text { реклама } \\
\text { в СМИ }\end{array}$ & $\begin{array}{c}\text { совет } \\
\text { знакомых }\end{array}$ & $\begin{array}{c}\text { все } \\
\text { источни } \\
\text { ки }\end{array}$ & Всего \\
\hline до 30 & $10(38,46 \%)$ & $12(46,15 \%)$ & $2(7,69 \%)$ & $2(7,69 \%)$ & $\mathrm{o}(0,0 \%)$ & 26 \\
\hline 31-40 & $8(42,11 \%)$ & $9(47,37 \%)$ & $2(10,53 \%)$ & o (o,o \%) & $\mathrm{o}(0,0 \%)$ & 19 \\
\hline 41-50 & $16(84,21 \%)$ & $\mathrm{O}(0,0 \%)$ & $2(10,53 \%)$ & $1(5,26 \%)$ & $\mathrm{o}(0,0 \%)$ & 19 \\
\hline $51-60$ & $4(18,18)$ & $3(13,64)$ & $4(18,18)$ & $2(9,09)$ & $9(40,91)$ & 22 \\
\hline Более & $14(66,67 \%)$ & $\mathrm{o}(0,0 \%)$ & $4(19,05 \%)$ & $2(9,52 \%)$ & $1(4,76 \%)$ & 21 \\
\hline Итого & $52(48,59 \%)$ & $24(22,42 \%)$ & $14(13,08 \%)$ & $7(6,54 \%)$ & $10(9,35 \%)$ & 107 \\
\hline
\end{tabular}

По результатам проверки статистических гипотез следует, что статистическая взаимосвязь двух анализируемых признаков существует (p=0,оооо). Наблюдается определенная связь между возрастом респондента и источниками информации об аппаратах для проведения ингаляций.

Потребителей в возрасте от 30 до 40 лет можно охарактеризовать как «максимально уверенных в себе», и не особенно желающих прислушиваться к неофициальным источникам. К мнению знакомых прислушиваются более 9 \% опрошенных старше 50 лет и 7,69 \% молодых анкетируемых (до 30 лет).

Самыми «недоверчивыми» оказались респонденты в возрасте 51-6о лет: многие из них (40,9 \%) использовали все виды информации для принятия решения. В остальных возрастных категориях предпочтения разделились: 84,21 \% респондентов в возрасте 41-50 лет и 66,67 \% респондентов в возрасте более 6о лет полагаются на мнение аптечных работников. Потребители до 40 лет наиболее часто изучают данные, представленные на 
официальных сайтах производителей медицинской техники (до 30 лет - 46,15 \%, до 40 лет 47,37 \% соответственно), для них также важны и консультации специалиста (38,46 \% и 42,11\% соответственно).

В целом респонденты предпочитают покупать ингаляционную технику в аптеке (71,45 \%) и в магазине медицинской техники $(21,5)$, интернет-магазинам доверяют лишь 8,41 \%.

Прослеживается взаимосвязь источника информации и места покупки аппарата для проведения ингаляции (табл. 3).

Статистическая взаимосвязь двух анализируемых признаков существует ( $\mathrm{p}=0,0004)$. Говоря о консультации аптечного работника, как о маркетинговом шаге в плане доведение информации до потенциального покупателя специалистом, важно отметить, что качественная, профессиональная консультация специалиста приводит однозначно к положительному результату. Респонденты, использующие для получения информации консультацию аптечного работника, в большинстве своем и покупку совершали в аптеке $(76,92 \%)$.

Менее трети «Пользователей» Интернет совершали покупки через Интернет (29,17 \%), предпочитая делать покупки в аптеке (37,5 \%) и в магазинах медицинской техники (33,33 \%). Респонденты, доверяющие рекламе, также предпочитали аптеки (64,29 \%) и магазины медицинской техники $(28,57 \%)$.

Таблица 3. Таблица сопряженности для признаков: источники информации при выборе типа ингалятора и место покупки

\begin{tabular}{|c|c|c|c|c|c|c|}
\hline \multirow{2}{*}{$\begin{array}{c}\text { Место } \\
\text { покупки }\end{array}$} & $\begin{array}{c}\text { Консультация } \\
\text { специалиста }\end{array}$ & $\begin{array}{c}\text { интернет-сайты } \\
\text { производтелей } \\
\text { продукции }\end{array}$ & $\begin{array}{c}\text { реклама в } \\
\text { сми }\end{array}$ & $\begin{array}{c}\text { совет } \\
\text { знакомых }\end{array}$ & $\begin{array}{c}\text { все } \\
\text { источники }\end{array}$ & Всего \\
\hline $\begin{array}{c}\text { медтехни } \\
\text { ка }\end{array}$ & $11(21,15 \%)$ & $8(33,33 \%)$ & $\begin{array}{c}4 \\
(28,57 \%)\end{array}$ & $0(0,0 \%)$ & о (o,o \%) & 23 \\
\hline $\begin{array}{c}\text { интернет- } \\
\text { магазин }\end{array}$ & $1(1,92 \%)$ & $7(29,17 \%)$ & $1(7,14 \%)$ & о (0,0 \%) & о (о,о \%) & 9 \\
\hline аптека & $40(76,92 \%)$ & $9(37,5 \%)$ & $9(64,29)$ & $7(100 \%)$ & $10(100 \%)$ & 75 \\
\hline Итого & $52(48,59 \%)$ & $24(22,42 \%)$ & $\begin{array}{c}14 \\
(13,08 \%)\end{array}$ & $7(6,54 \%)$ & $10(9,35 \%)$ & 107 \\
\hline
\end{tabular}

Респонденты, воспользовавшиеся всеми средствами информации, делали покупку исключительно в аптеке. Основываясь на ответах по вопросу: «Какими источниками информации вы пользовались при выборе медицинского прибора», только женщины отметили, что для принятия решения о покупке изучали все возможные источники информации. Необходимо иметь в виду эту особенность женского психологии и во время процесса покупки уделять покупательницам особое внимание, при предложении различных видов аппаратов предоставлять максимально полную информацию для принятия ими решения о покупке непосредственно в процессе беседы со специалистом и совершения данной покупки в данной торговой точке.

Данный вопрос можно рассмотреть и с позиции, где получали информацию покупатели. Более половины покупателей аптечной организации (53,33 \%) получают информацию непосредственно в аптеке, меньшая часть (по 12 \%) в СМИ и Интернете, 13,33 \% приходят в аптеку, изучив все источники информации.

\section{Выводы}

Анализ факторов, влияющих на выбор и приобретение аппаратов для ингаляций, показал, что основным фактором, определяющим покупку, является рекомендация врача. 
На этапе выбора типа ингаляционной техники большинство респондентов полагается на мнение аптечного работника, особенно покупатели, старше 60 лет и в возрасте от 41до 50. Производителям аппаратов следует учитывать, что покупатели до 40 лет активно изучают информацию на интернет-сайтах и предоставлять исчерпывающую информацию и обеспечивать формирование покупательских предпочтений.

Наиболее предпочтительным местом приобретения аппаратов, по мнению респондентов, являются аптечные организации.

Большинство респондентов предпочитают покупать ингаляционную технику в аптеке, следовательно, именно аптеки должны регулярно проводить маркетинговые исследования предпочтений покупателей. Грамотная и полноценная консультация аптечным работником потенциальных покупателей относительно параметров и характеристик аппаратов для проведения ингаляции является одним из маркетинговых шагов при продвижении медицинской техники. Именно женщинам необходимо предоставлять максимально полную информацию для принятия решения непосредственно в месте продажи.

\section{Примечания:}

1. Яковлева Н.В. Методики психологического исследования здоровьесберегающей деятельности субъекта [Электронный ресурс] / Н.В. Яковлева, В.В. Яковлев // Личность в меняющемся мире: здоровье, адаптация, развитие: сетевой журн. 2014. № 2 (5). Режим доступа: http://humjournal.rzgmu.ru/art\&id=84 (дата обращения: 31.12.2015).

2. Уланова Н.Н. Особенности здоровьесберегающего поведения и приверженности лечению у врачей на разных этапах профессионального становления / Н.Н. Уланова, Н.В. Яковлева // Российский медико-биологический вестник, 2015. №1. С.102-108.

3. Калинин Р.Е. Опыт исследования направленности личности и здорового образа жизни студентов региональных вузов [Электронный ресурс] / Р.Е. Калинин, Н.В. Яковлева, Д.В. Сочивко, А.И. Фролов, В.В. Яковлев, М.И. Разживина // Личность в меняющемся мире: здоровье, адаптация, развитие: сетевой журн. 2015. № 4 (11). Режим доступа: http://humjournal.rzgmu.ru/art\&id=173 (дата обращения: 31.12.2015).

4. Клищенко М.Ю. Инновации внедрения новых лекарственных форм в ассортимент лекарственных средств / М.Ю. Клищенко, Г.А. Харченко // Материалы ежегодной научной конференции университета. Рязань, 2011. С. 330-332.

5. Клищенко М.Ю. Информационные показатели в определении ассортимента аппаратов для диагностики и тест-аппаратов / М.Ю. Клищенко, Г.А. Харченко // Материалы ежегодной научной конференции, посвященной 70- летию основания Рязанского государственного медицинского университета имени академика И.П. Павлова под общ. ред. Заслуженного работника высшей школы Российской Федерации, проф. В.А.Кирюшина. Рязанский государственный медицинский университет им. академика И.П. Павлова. Рязань, 2013. С. 321-323.

6. Клищенко М.Ю. Маркетинговые исследования конкурентоспособности фармацевтической организации / М.Ю. Клищенко, Г.А. Харченко // Опыт и проблемы маркетинговой деятельности в российском предпринимательстве и бизнесе сборник статей XIV Всероссийской научно-практической конференции. Под редакцией Л.Н. Семерковой. Пенза, 2014. С. 12-15.

7. Клищенко М.Ю. Обновление и расширение ассортимента фармацевтических товаров / М.Ю. Клищенко, Г.А. Харченко // Материалы ежегодной научной конференции университета. Рязань, 2011. С. 326-328.

8. Клищенко М.Ю. Перспективы использования информационных технологий в полевых исследованиях / М.Ю. Клищенко, Г.А. Харченко // Здравоохранение: образование, наука, инновации Материалы Всероссийской научно-практической конференции с международным участием, посвященной 70-летию Рязанского государственного медицинского университета им. акад. И.П. Павлова. под редакцией Р.Е. Калинина. 2013. C. $69-70$.

9. Харченко Г.А. Зависимость конкурентоспособности фармацевтической организации от ассортимента новых товаров / Г.А. Харченко, М.Ю. Клищенко, И.В. Григорьева // Инновационное развитие России: проблемы и перспективы сборник статей 
III Международной научно-практической конференции. Под редакцией Т.В. Колосовой, О.А. Лузгиной. Пенза, 2014. С. 102-105.

10. Реброва О.Ю. Статистический анализ медицинских данных. Применение пакета прикладных программ Statistica. М.: МедиаСфера, 2003. 312с.

11. Grigorieva I.V. Statistical research of the medical preparations storage conditions among population / I.V. Grigorieva, V.V. Kovalenko, Nadir Ben Kafada // European researcher. 2012. Vol. 20, № 5-1. P.577-579.

12.Исследование отношения населения к использованию лекарственных препаратов с учетом срока годности / И.В. Григорьева, В.В. Коваленко, А.Н. Гаврилов и др. // Известия Сочинского государственного университета. 2012. № 3 (21). С. 208-213.

13. Statistical researches of some aspects of use medical preparations alter useby dates among population / I.V. Grigorieva, V.V. Kovalenko, A.N.Gavrilov et al. // European researcher. 2013. Vol. 48, №5-1. P.1270-1274.

14.Анализ использования дисконтной системы в аптечных организациях в зависимости от их категории и уровня конкуренции на основе статистической обработки результатов анкетного опроса / С.В. Семёнова, Г.А. Харченко, И.В. Григорьева и др. // Медицинский альманах. 2015. № 3. С. 213-215.

15. Bykov A.T. Hemodynamics State at Different Modes of Systemic Air Cryogenic Exposure / A.T. Bykov, V.A. Rybkina, V.V. Kovalenko // European Researcher, 2012,vol.34, №11-2. P. 19291934.

16.Bykov A.T. Definition of regional dependence of activity antioxidative enzymes means of the dispersive analysis / A.T. Bykov, I.V. Vashtak, V.V. Kovalenko // European Researcher, 2011, vol.7, №5-1. P. 584-586.

\section{References:}

1. Yakovleva N.V. Metodiki psihologicheskogo issledovaniya zdorovesberegayuschey deyatelnosti subekta [Elektronnyy resurs] / N.V. Yakovleva, V.V. Yakovlev // Lichnost v menyayuschemsya mire: zdorove, adaptaciya, razvitie: setevoy zhurn. 2014. № 2 (5). Rezhim dostupa: http://humjournal.rzgmu.ru/art\&id=84 (data obrascheniya: 31.12.2015).

2. Ulanova N.N. Osobennosti zdorovesberegayuschego povedeniya i priverzhennosti lecheniyu $\mathrm{u}$ vrachey na raznyh etapah professionalnogo stanovleniya / N.N. Ulanova, N.V. Yakovleva // Rossiyskiy mediko-biologicheskiy vestnik, 2015. №1. S.102-108.

3. Kalinin R.E. Opyt issledovaniya napravlennosti lichnosti i zdorovogo obraza zhizni studentov regionalnyh vuzov [Elektronnyy resurs] / R.E. Kalinin, N.V. Yakovleva, D.V. Sochivko, A.I. Frolov, V.V. Yakovlev, M.I. Razzhivina // Lichnost v menyayuschemsya mire: zdorove, adaptaciya, razvitie: setevoy zhurn. 2015. № 4 (11). Rezhim dostupa: http://humjournal.rzgmu.ru/art\&id=173 (data obrascheniya: 31.12.2015).

4. Klischenko M.Yu. Innovacii vnedreniya novyh lekarstvennyh form $\mathrm{v}$ assortiment lekarstvennyh sredstv / M.Yu. Klischenko, G.A. Harchenko // Materialy ezhegodnoy nauchnoy konferencii universiteta. Ryazan, 2011. S. 330-332.

5. Klischenko M.Yu. Informacionnye pokazateli v opredelenii assortimenta apparatov dlya diagnostiki i test-apparatov / M.Yu. Klischenko, G.A. Harchenko // Materialy ezhegodnoy nauchnoy konferencii, posvyaschennoy 70- letiyu osnovaniya Ryazanskogo gosudarstvennogo medicinskogo universiteta imeni akademika I.P. Pavlova pod obsch. red. Zasluzhennogo rabotnika vysshey shkoly Rossiyskoy Federacii, prof. V.A.Kiryushina. Ryazanskiy gosudarstvennyy medicinskiy universitet im. akademika I.P. Pavlova. Ryazan, 2013. S. 321-323.

6. Klischenko M.Yu. Marketingovye issledovaniya konkurentosposobnosti farmacevticheskoy organizacii / M.Yu. Klischenko, G.A. Harchenko // Opyt i problemy marketingovoy deyatelnosti $\mathrm{v}$ rossiyskom predprinimatelstve $\mathrm{i}$ biznese sbornik statey XIV Vserossiyskoy nauchno-prakticheskoy konferencii. Pod redakciey L.N. Semerkovoy. Penza, 2014. S. 12-15.

7. Klischenko M.Yu. Obnovlenie i rasshirenie assortimenta farmacevticheskih tovarov / M.Yu. Klischenko, G.A. Harchenko // Materialy ezhegodnoy nauchnoy konferencii universiteta. Ryazan, 2011. S. 326-328.

8. Klischenko M.Yu. Perspektivy ispolzovaniya informacionnyh tehnologiy $\mathrm{v}$ polevyh issledovaniyah / M.Yu. Klischenko, G.A. Harchenko // Zdravoohranenie: obrazovanie, nauka, 
innovacii Materialy Vserossiyskoy nauchno-prakticheskoy konferencii $\mathrm{s}$ mezhdunarodnym uchastiem, posvyaschennoy 70-letiyu Ryazanskogo gosudarstvennogo medicinskogo universiteta im. akad. I.P. Pavlova. pod redakciey R.E. Kalinina. 2013. S. 69-70.

9. Harchenko G.A. Zavisimost konkurentosposobnosti farmacevticheskoy organizacii ot assortimenta novyh tovarov / G.A. Harchenko, M.Yu. Klischenko, I.V. Grigoreva // Innovacionnoe razvitie Rossii: problemy i perspektivy sbornik statey III Mezhdunarodnoy nauchno-prakticheskoy konferencii. Pod redakciey T.V. Kolosovoy, O.A. Luzginoy. Penza, 2014. S. 102-105.

10. Rebrova O.Yu. Statisticheskiy analiz medicinskih dannyh. Primenenie paketa prikladnyh programm Statistica. M.: MediaSfera, 2003. 312s.

11. Grigorieva I.V. Statistical research of the medical preparations storage conditions among population / I.V. Grigorieva, V.V. Kovalenko, Nadir Ben Kafada // European researcher. 2012. Vol. 20, № 5 -1. P.577-579.

12. Issledovanie otnosheniya naseleniya $\mathrm{k}$ ispolzovaniyu lekarstvennyh preparatov s uchetom sroka godnosti / I.V. Grigoreva, V.V. Kovalenko, A.N. Gavrilov i dr. // Izvestiya Sochinskogo gosudarstvennogo universiteta. 2012. № 3 (21). S. 208-213.

13. Statistical researches of some aspects of use medical preparations alter useby dates among population / I.V. Grigorieva, V.V. Kovalenko, A.N.Gavrilov et al. // European researcher. 2013. Vol. 48, №5-1. P.1270-1274.

14. Analiz ispolzovaniya diskontnoy sistemy $\mathrm{v}$ aptechnyh organizaciyah $\mathrm{v}$ zavisimosti ot ih kategorii i urovnya konkurencii na osnove statisticheskoy obrabotki rezultatov anketnogo oprosa / S.V. Semyonova, G.A. Harchenko, I.V. Grigoreva i dr. // Medicinskiy almanah. 2015. № 3. S. 213-215.

17. Bykov A.T. Hemodynamics State at Different Modes of Systemic Air Cryogenic Exposure / A.T. Bykov, V.A. Rybkina, V.V. Kovalenko // European Researcher, 2012,vol.34, №11-2. P. 1929-1934.

18. Bykov A.T. Definition of regional dependence of activity antioxidative enzymes means of the dispersive analysis / A.T. Bykov, I.V. Vashtak, V.V. Kovalenko // European Researcher, 2011, vol.7, №5-1. P. 584-586.

УДК 615.473.9:615.835.5; 33

\title{
Изучение факторов, влияющих на выбор аппаратов для проведения ингаляций на основе статистической обработки результатов анкетного опроса
}

\author{
${ }^{1}$ Галина Алексеевна Харченко \\ 2 Марина Юрьева Клищенко \\ 3 Ирина Викторовна Григорьева \\ 4 Владимир Васильевич Коваленко \\ 5 Светлана Викторовна Семёнова
}

1 Рязанский государственный медицинский университет имени академика И.П. Павлова, Российская Федерация

390026 г. Рязань, ул. Высоковольтная, д. 9

Кандидат биологических наук, доцент

E-mail: kmarina62@mail.ru

2 Рязанский государственный медицинский университет имени академика И.П. Павлова, Российская Федерация

390026 г. Рязань, ул. Высоковольтная, д. 9

Ассистент

E-mail: kmarina62@mail.ru

3 Рязанский государственный медицинский университет имени академика И.П. Павлова, Российская Федерация

390026 г. Рязань, ул. Высоковольтная, д. 9

Кандидат фармацевтических наук, доцент

E-mail: i.grigorieva62@mail.ru

4 Сочинский государственный университет, Российская Федерация

Кандидат технических наук, доцент 
E-mail: vlvas@mail.ru

5 Рязанский государственный медицинский университет имени академика И.П. Павлова, Российская Федерация

390026, г. Рязань, ул. Высоковольтная, д. 9

Ассистент

E-mail: SV-tmb@yandex.ru

Аннотация. Авторами поставлена цель, изучить факторы, влияющие на выбор покупателей аппаратов для проведения ингаляции, на основе статистической обработки результатов анкетного опроса покупателей, проанализировать взаимосвязь между факторами, влияющими на выбор и покупку аппарата и половозрастными характеристиками потенциальных покупателей. Выявлена роль врача, работника аптеки, интернет-сайтов в процессе выбора, мнение потребителей разных возрастных категорий о наиболее предпочтительных источниках информации об аппаратах для проведения ингаляции, определены предпочтения покупателей при выборе места совершения покупки аппаратов для проведения ингаляции. Показана особенность респондентов женского и мужского пола по вопросам использования источников информации и принятия решения о покупке.

Ключевые слова: аппараты для проведения ингаляции, потребительские свойства, статистическая обработка, анкетирование, маркетинговые исследования, аптечная организация. 